\title{
Assessing hospital cost data quality in the quest for a cost-effective health care
}

\author{
Margit Malmmose ( $\nabla$ mmalmmose@mgmt.au.dk) \\ Aarhus University https://orcid.org/0000-0002-8507-0731 \\ Jogvan Pauli Lydersen \\ Ringkjøbing Landbobank
}

Research article

Keywords: hospitals, cost accounting, DRG, value-based health care

Posted Date: December 1st, 2020

DOl: https://doi.org/10.21203/rs.3.rs-113830/v1

License: (c) (i) This work is licensed under a Creative Commons Attribution 4.0 International License.

Read Full License

Version of Record: A version of this preprint was published at BMC Health Services Research on August 18th, 2021. See the published version at https://doi.org/10.1186/s12913-021-06807-4. 


\section{Abstract}

Background: The objective is to examine hospital cost accounts in order to understand the foundation upon which large-scale health care decisions are based. More specifically, the aim is to add insights to accounting practices and their applicability towards a newly establish value-based agenda with a focus on patient-level cost data.

Methods: We apply a cost accounting framework developed to position and understand hospital cost practices in relation to government requirements. Allocated cost account data from 2015 from all Danish hospitals were collected and analysed.

Results: We find exceedingly aggregated department-level data that are not tied to patient information. We further observe variations in integrated cost centre definitions and allocation methods, as well as a melding of both overhead and indirect costs with direct costs at the department level. Additionally, we find large structural variances within hospitals.

Conclusions: The findings raise concern about the cost accounts' ability to provide valid information in health care decision-making due to a lack of transparency. Additionally, standardisation of costs stemming from hospitals with large organisational differences has significant implications on the fairness of resource allocation and decision-making at large. Thus, for hospitals to become more cost efficient, a substantially more detailed cost account system is essential.

\section{Background:}

This paper addresses cost data quality in health care (1-4). The implications of cost accounting are vital both in a newly defined value-based agenda in hospital management $(5,6)$ as well as the traditional diagnosis-related group (DRG) volume-driven cost accounting approach $(3,4)$. We are concerned with the transparency and quality of cost data in the trend of transiting from volume- to value-driven health care because this transition provides the foundation for our decision-making at large (7). We examine Danish hospitals' cost accounting, which provides the current foundation for DRG rate calculation $(3,8)$ and acts as a basis for further developing a patient-level cost data approach. The objective is to examine hospital cost accounting quality in order to understand hospital- and sector-level implications. We specifically evaluate allocation methods, applied locally by the hospitals, which is then distributed to sector-level application for benchmarking and resource allocation. We discuss the concomitant implications of the mode of cost allocation. This study draws on the conceptual framework of Tan et al. (4), which mirrors management accounting costing theory. The framework of Chapman et al. (3) is also applied to position and stipulate the examined focal point.

This type of national examination of hospital cost accounts is important for several reasons. First, Chapman et al. (3) and Kaplan et al. (7) emphasise the significance of evaluating costing practices and their relation to the wider context. Second, we develop a new examination on previous studies of Raulinajtys-Grzybek (9) and Ankjær-Jensen et al. (10), who investigated the Danish cost accounting 
model in 2005-2006. However, the cost accounting model was altered with the structural reform in 2007 (11), which warrants a basis for re-examination. Additionally, Tiemann (12) finds that the Danish hospital data are highly aggregated and, therefore, had to be excluded from the cross-country analysis of hospitalisation costs within acute myocardial infarction, which is also indicated by a large number of overhead costs compared to other nations (1). Yet, the cost accounting comprised $3.14 \%$ of Danish GDP in 2015 (13). Thus, the methods for allocating these costs and their influence on sector-level decisionmaking is crucial in relation to health care cost-effectiveness. Additionally, the National Audit Office of Denmark highlighted concerns with the alignment and transparency of the costing information from hospitals (14). The Danish Health Data Authority has accommodated the National Audit Office's concerns regarding alignment by composing a cost allocation guideline for hospitals. Although in recent years, Denmark shares the interest and concern of value-based agenda (5), the cost accounts remain unaltered. The findings are useful in the continuous health care costing debate where an increasing international and theoretical focus is put on time-driven activity-based costing (TDABC) as a solution $(6,15)$.

The findings illuminate discrepancies in cost account procedures. Most obvious is the aggregate level of data that do not appear to be associated with patient data prior to or during the cost allocations, which is problematic in establishing patient-level cost data (7). Additional findings on the variances in hospital structural set-ups reflected in the cost account data, as well as variances in types and numbers of cost centres, are present. Thus, the cost accounting system is poorly developed and lacks transparency, which is problematic in a wide spectrum of hospital and sector decision-making.

\section{Methods:}

Chapman et al. (3) provide a framework illustrating the relationships between DRG, costing guidance, costing practices and clinical practices. These four elements are interrelated. This study focuses on the costing practice, which Fig. 1 refers to as 'Accounting information'. According to Chapman et al. (3), the costing practices are influenced by costing guidance from the governmental level. The relevant instructions from the Danish costing guidance will be illuminated below. The clinical practices influence costing practices regarding possible and identified cost drivers, which are factors that incur costs, such as labour hours or square meters of a room. This present study focuses on the cost accounting and the actual cost allocation methods. Thus, the hospitals' cost drivers are also evaluated and described.

Costs included in DRG rate calculations include direct costs, which are department costs allocated directly to the patient and indirect costs, which are department overhead costs allocated to the patient by using a cost driver. Overhead costs are typically administrative and facility management, which cannot be directly linked to a specific patient. Finally, we have the category of hospital overhead costs, which are allocated to the medical departments. There are three different methods for allocating overhead costs: direct, step-down and reciprocal (16). Direct allocation is directly allocated to medical departments without interaction between service departments. The step-down method allocates one service department, for example IT, to another service department, for example HR, which is then allocated to the medical departments. The reciprocal method takes bilateral deliveries between the departments into 
account. For example, IT's use of HR and HR's use of IT before allocating the costs to the medical departments.

Finally, Tan et al. (4) describe four methods for calculating the direct department costs per patient. These four methods are placed in a matrix identifying hospital service accuracy on one axe and accuracy of valuating the services on the other axe. Gross- and micro-costing identify the accuracy of hospital service with high valuation accuracy, whereas gross-costing is less accurate in identification than micro-costing. The other two methods are top-down versus bottom-up, with less valuation of hospital services where top-down values inpatient days per average patient (less identification of hospital service), and bottom-up values inpatient days per individual patient (better identification of hospital service). We apply these concepts in our evaluation of the Danish hospitals' cost accounts to identify transparency and standardisation, which are prerequisites for a successful DRG system $(3,17)$.

\section{Data}

This study evaluates all Danish hospitals' cost allocation accounts from 2015, which are distributed to the Danish Health Data Authority by the hospitals. There are altogether cost allocation accounts from 20 hospitals or merged hospitals. The collected cost allocation accounts comprise a master document developed by the Health Data Authority. This Microsoft Excel document includes eight interrelated sheets: a cost map, where the different cost centres are identified and coded to be either external, support or department centres. The support centres are overhead costs, divided into four different levels predefined by the Health Data Authority as a guided sequential step-down method. A sheet for cost allocation accounts comprises accounts from the fiscal reporting. Sheet 4 is a guided cost driver sheet where the organisation can mark the type of cost drivers applied. Sheet 3 comprises the support centres in the rows, whereas all the cost centres are identified in the columns. It is in this sheet that the actual percentage is inserted identifying how much of the support centre costs is allocated to which cost centres. Here, it is possible to specifically identify which cost driver is applied for each support centre allocation. Thus, it is those sheets that are analysed and evaluated. The remaining four sheets are summaries or guidelines.

The cost accounting is one vital part of these calculations. The other part is hospital activity, which is provided by patient administrative systems and clinical transversal databases. The patient administrative systems contain basic data on each treatment a patient receives, whereas the clinical databases encompass the entire course of treatments that a patient has received per discharge (18). The dataflow is shown in Fig. 1.

$>$ insert Fig. $1<$

The patient and service information is kept in local department databases, which have received prodigious focus due to the fact that physicians, nurses and other healthcare staff work directly with them (14). The cost accounting is, in contrast to the activity data, completed by back-office management accountants, who are not in contact with the patient administrative systems; hence, the preparation of the cost allocation is decoupled from the direct activity registration at the hospital level. 
Additionally, two meetings were held with a hospital cost allocation account responsible in order to clarify the procedures and concepts applied. The guideline report from the Danish Health Data Authority has, moreover, created the foundation for understanding the cost accounting. Finally, some of the issues raised during the evaluation were verified or clarified by a cost account responsible at the Danish Health Data Authority.

Inpatient and outpatient activity were also added to the results table in order to relate the total costs to activity and understand the structural differences between the hospitals.

\section{Results:}

Table 1 shows the aggregated findings of evaluating the 20 hospitals' cost accounting reports. It can be observed that one region (the smallest in Denmark) is reporting its hospital costs collectively. The other Regions report their hospitals' cost accounting in four to six reports. Each of these reports comprises, on average, two physical hospital units. The inpatient and outpatient activities were identified as a size and activity indicator. These numbers stem from the actual patient administrative systems, which are used as an activity basis for DRG rate calculations (see Fig. 1). The cost allocation reports show the direct and indirect costs in absolute numbers. The direct costs comprise department costs. Thus, there is a distinction between direct department costs and direct diagnosis costs. In the cost allocation accounts, we find no detailed diagnosis costs. Therefore, the direct costs exist on an aggregated department level, illustrating a gross- rather than micro-costing approach according to Tan et al's (4) conceptual framework. We furthermore identify substantial variations in activity level and costs. The largest organisational account unit has total costs of nearly 8 billion DKK, whereas the smallest unit only has costs of 438 million DKK. On average, the indirect costs account for $25 \%$ of total costs, but on an organisational level, this varies from $21-29 \%$. The number of department cost centres varies significantly (53-291). These results illustrate large structural differences as well as the services provided.

Level 1 support cost mainly consists of one cost centre, namely regional costs. Level 2 support cost centres vary from one to seventeen cost centres. Most units have IT-related costs in addition to those related to hospital administration. Apart from these two categories, there are further substantial variations. Some hospital units separate the quality department costs, financial department costs, HR costs and/or energy. The organisational unit in Region E was found to have 17 Level 2 cost centres because their account sheet is on a regional level comprising several hospital units, the administrative costs of which are divided into separate categories, which resembles a more detailed micro-costing approach.

Generally, we identify that overhead costs, comprising regional and hospital administration, are melded with indirect costs that are typically activity-based support centre related. Thus, a clear distinction of overhead and indirect costs is not maintained. Level 1 costs are all allocated to the final cost centres using earnings before interest, taxes, depreciation and amortisation (EBITDA) as a cost driver. However, four hospitals allocate the full regional costs to level 2 (with 100\%), which are then distributed to the 
medical departments. Further, Level 2 costs typically use EBITDA as a cost driver. Level 1 costs comprise a total of $55 \%$ of the support centre costs and $13 \%$ of the total costs. Therefore, the coding and allocation method has a significant influence on the department costs. For some departments, a standardised cost allocation may alter their expenses substantially.

Level 3 cost centres comprise indirect costs. Hence, these support functions are more easily defined by activity and, thereby, differently distributed to the medical departments depending on the activity (i.e. service usage). The cost drivers applied are typically bed days, which are mainly used for allocating kitchen costs; time usage and square meters are also frequently applied, with the latter factor being used to allocate technical department costs. Level 4 cost centres mainly apply actual activity as an indicator for distributing costs. Examples of Level 4 cost centres are blood banks, immunisation, patient hotels, clinical genetic departments, pharmacies and anaesthesia.

Although the guideline instructs the hospital units to apply a step-down model in allocating costs, five out of twenty organisational units apply a significant amount of the Level 1 and 2 costs directly to the departments. Thus, the cost allocation method is not aligned across hospital units and neither are cost centre definitions.

Direct cost methodology cannot be explicitly identified in the cost accounts because this would demand service identification, which is separate information in the patient administrative and clinical databases. This analysis shows that the cost estimation lacks detail because they are not registered per patient or diagnosis. Hence, there is a lack of activity-based costing registration. Thereby, and according to Tan et al.'s (4) conceptual framework, we can identify the accuracy of valuation of hospital services as being on a highly aggregate level. Assuming a particularly accurate service identification level, a top-down microcosting method is applied. Thus, averages are applied in valuing patient services. This approach contradicts the findings of Chapman et al. (3), who state that Denmark applies a bottom-up patient-level costing approach; this is not the case when evaluating the cost allocation foundation. The cost accounts are linked to patients at a later stage combining these analysed cost data with patient activity data. Thus, the approach is performed at an aggregate level in the central organisation of the Health Data Authority.

$>$ Insert table $1<$

\section{Discussion:}

Overall, three areas of cost account challenges can be identified in the above cost account evaluation. 1) the hospital structure in Denmark influencing the cost account reporting and, thereby, 2) the usage of different cost centre definitions as well as allocation methods, and finally, 3) the inclusion of overhead costs and indirect costs with direct costs and the implications of aggregated costing data. These findings have substantial implications for the validity of cost account quality in DRG rate estimates and also for applying patient-level costing to estimate total resource use across departments, forming part of a valuebased agenda (6). 
The descriptive numbers of inpatient and outpatients as well as costs indicate the hospital organisation's size. We see large differences in these sizes and additional set-ups. For example, Region E only has one set of cost accounting reports. Following the structural reform in 2007, a major focus has been mergers and specialisation in hospitals $(11,19)$. Thus within one region, a department in one hospital specialises in, for example, gall bladder operations mixed with other orthopaedic surgeries, whereas in another region, gall bladder operations may be placed in a hospital with heart surgery. Thus, due to hospital heterogeneity, a skewness in allocation of costs may exist, supported by the fact that the cost weights do not reflect the hospital treatment. This issue is illuminated by Ankjær-Jensen et al. (10), who claim major uncertainty in the statement of cost centres at the individual hospitals. This present evaluation identifies continued uncertainty ten years later. We further note a structural variation, which may substantiate this uncertainty. Different organisational set-ups challenge standardisation. Thus, a contradiction appears in the central wish from the Health Ministry and the Health Data Authority to align cost accounting and an ability to accomplish cost-effective decision-making in resource allocation as well as holding hospitals accountable for a specific activity level being distorted by geographical and regional structural differences.

According to Chapman et al. (3, p. 357), the government, and in this case the Danish Health Data Authority, influences costing practices through guidelines. Yet, we witness how these guidelines become decoupled from the actual costing practice, and the cost accounts show aggregated calculations and accounts (gross-costing). Thus, there is a lack of standardisation in the cost accounting foundation, both for the DRG rate calculations that influence fairness in the following application of DRGs for benchmarking, but also for future different patient-level cost initiatives. Both the DRG rates and the valuebased agenda require strongly standardised costing practices $(3,7)$ in order to represent fairness and to enable comparison. Additionally, the calculations require adjustment for knowledge on patient activity and progress so that they can be fair, but this approach is absent in these cost accounts. Consequently, the different cost allocation procedures add skewness to cost information applicability.

Finally, melding overhead and indirect costs with direct costs influences cost transparency. Thereby, the ability for department management to influence measures upon which the departments are accounted for is not present. Although these practices appear to be common in DRG cost accounting, the practices contradict some of the basic management accounting principles that are essential in the value-based agenda (6). It is only direct and indirect costs (i.e., level 3 and 4 support costs in the empirics) that vary with actual patient activity in the medical departments. Level 1 and 2 costs are administrative overhead in nature, and they are decoupled from department activity. When these types of costs are allocated to departments, it implies a full costing system (20) and not an activity-based system, as illustrated by Kaplan and Witkowski (6). Thereby, the medical departments lack influence on the patient activity costing. Additionally, activity-based costing requires that direct and indirect costs are separated according to the cost objects' use of resources $(6,21)$. In the current cost accounts from the Danish hospitals, this is not the case. All costs are allocated on a department level, which implies a highly aggregated cost information system with no primary relationship between the patient service and actual costs. The cost accounts, therefore, allocate service activity on an organisational level and not on a detailed level, which 
is required for activity-based costing (21). King et al. (22) and Balakrishnan et al. (15) evaluate several activity-based costing systems in health care, whereas none of these defined activity costs centre on the department level.

Due to the recent interest in a value-based agenda, a focus on the entire patient continuity of care cost (23) is essential and differs from DRG costing, which focuses on the cost of hospital events (inpatient admissions and outpatient visits). This new approach warrants the increasing relevance of investigating the patient's total use of resources across hospital departments (and ideally for all healthcare providers), which has been empirically and theoretically lacking (6). Kaplan and Porter (24) suggest the application of TDABC, which seeks to allocate costs according to the core activities, the patient's medical condition, rather than medical and surgical specialities $(6,7)$. This strategy will better inform patient-related decision-making, both on a financial hospital level and related patient treatments. Thus, whereas Tan et al. (4) and Chapman \& Cahan (2) emphasise the hospitals' cost accounting systems as a pertinent managerial foundation because it informs hospitals' and central authorities' decisions, the costing information becomes even further relevant in a value-based agenda.

\section{Conclusions:}

We study all cost accounts from Danish hospitals in 2015. These cost accounts lay the foundation for different types of calculations, such as DRG rates. The accounting numbers are implemented in calculations used for benchmarking, resource allocation and management control. Therefore these numbers are significant and has great implications. We find that the exceedingly aggregate hospital department level cost data is not tied to patient nor diagnostic information, which contradicts policy intentions both regarding DRGs as well as value-based health care. We find large structural variances in the different hospital cost accounts which distort their applicability for national standard measures and thus health care decision-making. Finally, overhead- and indirect costs are melded with direct costs which distorts department managers' accountable ability. Thus, in order to improve reliable decision making in, we propose and encourage substantially more practical emphasis on costing systems at the hospital level. Hospital accounting reports and other calculative reports on the hospital level are often assumed to be correct $(25,26)$; however, we identify remarkable discrepancies that ultimately influence decisionmaking. For hospitals to become more cost-efficient, a significantly more detailed cost account system is essential. This examination is, therefore, not only directed to the research society on health care costing but should also act as informational to policy-makers and hospital managers, an approach that is further called for by Chapman (27). Future research is vital for identifying the actual magnitude of the identified cost data quality implications. Future studies may either analyse costing data in more detail or qualitatively pursue an understanding of the underlying incentive system. Additionally, it is necessary to develop better holistic accounting solutions for public health care systems and inform decision-makers about DRGs limitations and the detailed costing requirements for implementing patient-level cost data.

\section{Declarations}




\section{Funding:}

There is NO funding provided for this research.

\section{Conflict of interest:}

The authors certify that they have NO affiliations with or involvement in any organization or entity with any financial interest (such as honoraria; educational grants; participation in speakers' bureaus; membership, employment, consultancies, stock ownership, or other equity interest; and expert testimony or patent-licensing arrangements), or non-financial interest (such as personal or professional relationships, affiliations, knowledge or beliefs) in the subject matter or materials discussed in this manuscript.

\section{Access to data}

On request at Harvard Dataverse: https://doi.org/10.7910/DVN/TJBC83

\section{References}

1. Chapman C, Kern A, Laguecir A, Quentin W. Management accounting and efficiency in health services: the foundational role of cost analysis. In: Cylus J, Papanicolas I, Smith PC, editors. Health system efficiency: How to make measurement matter for policy and management. University of Bristol: World Health Organisation; 2016. p. 75-98.

2. Chapman $\mathrm{C}$, Cahan $\mathrm{S}$. Researching accounting in health care: considering the nature of academic contribution. Accounting \& Finance. 2015;55(2):397-413.

3. Chapman C, Kern A, Laguecir A. Costing Practices in Healthcare. Accounting Horizons. 2014;28(2):353-64.

4. Tan SS, Geissler A, Serdén L, Heurgren M, van Ineveld BM, Redekop WK, et al. DRG systems in Europe: variations in cost accounting systems among 12 countries. European Journal of Public Health. 2014;24(6):1023-8.

5. Højgaard B, Wolf RT, Bech M. Alternative styrings- og afregningsmodeller for sygehuse med afsæt i værdibaseret styring. In: KORA, editor. Copenhagen: Det Nationale Institut for Kommuners og Regioners Analyse og Forskning; 2016.

6. Kaplan RS, Witkowski ML. Better accounting transforms health care delivery. Accounting Horizons. 2014;28(2):365-83.

7. Kaplan RS, Porter ME, Frigo ML. Managing healthcare costs and value. Strategic Finance: Institute of Management Accountants; 2017. p. 24.

8. The Danish Health Data Authority (Sundhedsdatastyrelsen). Cookbook (Kogebog) - Hospital cost accounting guideline. The Danish Health Data Authority (Sundhedsdatastyrelsen); 2016. 
9. Raulinajtys-Grzybek M. Cost accounting models used for price-setting of health services: an international review. Health policy (Amsterdam, Netherlands). 2014;118(3):341.

10. Ankjær-Jensen A, Rosling P, Bilde L. Variable prospective financing in the Danish hospital sector and the development of a Danish case-mix system. Health Care Management Science. 2006;9(3):259-68.

11. Christiansen T. Ten years of structural reforms in Danish healthcare. Health Policy. 2012;106:114-9.

12. Tiemann 0 . Variations in hospitalisation costs for acute myocardial infarction - a comparison across Europe. Health Economics. 2008;17(S1):S33-S45.

13. The Danish Statistic Bank. Danish Gross Domestic Product (GDP). 2017.

14. The National Audit Office of Denmark (Rigsrevisionen). Beretning til Statsrevisorerne om DRGsystemet (Review on the DRG system for the Government Auditors). 2011.

15. Balakrishnan R, Koehler DM, Shah AS. TDABC: Lessons from an Application in Healthcare. 2018;32(4):31-47.

16. Horngren CT, Datar SM, Rajan MV. Cost accounting : a managerial emphasis. 14. global ed. ed. Boston: Pearson; 2012. 892 p.

17. Busse R. Diagnosis-related groups in Europe: moving towards transparency, efficiency, and quality in hospitals. 2011. In: European Observatory on Health Systems and Policies series [Internet]. Maidenhead: Open University Press; [458]. Available from: https://www.statsbiblioteket.dk/au/\#/search?query=recordID\%3A\%22ebog_ssj0000634165\%22.

18. Department of Health documentation. Takstsystem - vejledning. In english 'Rate system - guideline'. In: Body DHDG, editor. 2016.

19. Tanggaard Andersen P, Jensen J-J. Healthcare reform in Denmark. Scandinavian Journal of Public Health. 2010;38(3):246-52.

20. Chan YC. Improving hospital cost accounting with activity-based costing. Health care management review. 1993;18(1):71-7.

21. Demski JS. Managerial uses of accounting information. 2. edition ed. New York: Springer; 2010. 494 p.

22. King M, Lapsley I, Mitchell F, Moyes J. Costing needs and practices in a changing environment: The potential for ABC in the NHS. Financial Accountability \& Management. 1994;10(2):143-61.

23. Leung TI, van Merode GG. Value-Based Health Care Supported by Data Science. In: Kubben $P$, Dumontier M, Dekker A, editors. Fundamentals of Clinical Data Science. Cham: Springer International Publishing; 2019. p. 193-212.

24. Kaplan RS, Porter ME. How to solve the cost crisis in health care. Harvard business review: Harvard Business Review; 2011. p. 46.

25. Busse R, Geissler A, Quentin W, Wiley M, editors. Diagnosis-Related Groups in Europe: Moving towards transparency, efficiency and quality in hospitals. . Berkshire: Berkshire, Open University Press McGraw-Hill Education; 2011. 
26. Chua WF, Preston AM. Worrying about accounting in health care. Accounting, Auditing \& Accountability Journal. 1994;7(3):4-17.

27. Chapman CS. Researching accounting in health care: considering the nature of academic contribution. 2015;55(2):397-413.

\section{Tables}

\section{Table l: Cost accounting report findings}

\begin{tabular}{|c|c|c|c|c|c|c|c|c|c|c|c|c|c|}
\hline $\begin{array}{l}\text { Organisational Unit } \\
\text { for cost accounts }\end{array}$ & Region & $\begin{array}{l}\text { In Patient } \\
\text { Activity* }\end{array}$ & $\begin{array}{l}\text { Out Patient } \\
\text { Activity" }\end{array}$ & Direct costs & Indirect costs & Total rate based costs & $\begin{array}{l}\text { Number of } \\
\text { department cost } \\
\text { centers }\end{array}$ & $\begin{array}{l}\text { Level1 } \\
\text { support cost } \\
\text { centers }\end{array}$ & $\begin{array}{l}\text { Leve/2 } \\
\text { support cost } \\
\text { centers }\end{array}$ & $\begin{array}{l}\text { Level3 } 3 \\
\text { support cost } \\
\text { centers }\end{array}$ & $\begin{array}{l}\text { Level } 4 \\
\text { support } \\
\text { cost } \\
\text { centers }\end{array}$ & $\begin{array}{l}\text { Total Support } \\
\text { cost centers }\end{array}$ & $\begin{array}{l}\text { Method ap plied in } \\
\text { allocation of support costs }\end{array}$ \\
\hline 1 & A & 115644 & 819123 & 5.176 .250 .045 & 1.763 .911 .170 & 6.940 .161 .215 & 216 & 1 & 7 & 20 & 15 & 43 & $\begin{array}{l}\text { Direct method mixed with } \\
\text { stepdown method }\end{array}$ \\
\hline 2 & A & 83285 & 348775 & 2.179 .057 .665 & 762.969 .006 & 2.942 .026 .671 & 87 & 1 & 3 & 15 & 1 & 20 & $\begin{array}{l}\text { Direct method mixed with } \\
\text { stepdown method }\end{array}$ \\
\hline 3 & A & 64404 & 367688 & 1.890 .066 .586 & 740.352 .723 & 2.630 .419 .309 & 72 & 1 & 3 & 11 & 1 & 16 & Stepdown method \\
\hline 4 & A & 8822 & 45031 & 316.528 .965 & 121.973 .705 & 438.502 .670 & 46 & 1 & 1 & 6 & - & 8 & Stepdown method \\
\hline 5 & A & 115646 & 770421 & 3.655 .509 .804 & 1.110 .991 .198 & 4.766 .501 .002 & 111 & 1 & 1 & 18 & 2 & 22 & Stepdown method \\
\hline 6 & A & 81151 & 296014 & 1.969 .489 .090 & 585.319 .321 & 2.554 .808 .411 & 100 & 1 & 2 & 2 & 2 & 7 & Stepdown method \\
\hline 7 & B & \multirow{4}{*}{238620} & \multirow{4}{*}{929026} & 862.207 .044 & 317.394 .975 & 1.179 .602 .019 & 56 & 1 & 2 & 4 & - & 7 & Stepdown method \\
\hline 8 & B & & & 2.635 .142 .417 & 679.531 .497 & 3.314 .673 .914 & 112 & 2 & 2 & 3 & - & 7 & Stepdown method \\
\hline 9 & B & & & 2.033.639.571 & 602.379 .841 & 2.636 .019 .413 & 71 & 1 & 2 & 6 & 9 & 18 & Stepdown method \\
\hline 10 & B & & & 632.358 .533 & 256.457 .460 & 888.815 .993 & 66 & 1 & 2 & 1 & 2 & 6 & Stepdown method \\
\hline 11 & c & 107418 & 876507 & 5.339 .372 .658 & 1.496 .903 .856 & 6.836 .276 .514 & 125 & 1 & 3 & 5 & 4 & 13 & Stepdown method \\
\hline 12 & c & 47601 & 282060 & 1.382 .763 .888 & 449.469 .928 & 1.832 .233 .815 & 98 & 1 & 3 & 6 & 1 & 11 & $\begin{array}{l}\text { Direct method mixed with } \\
\text { stepdown method }\end{array}$ \\
\hline 13 & c & 40655 & 293221 & 1.389.776.166 & 430.673 .637 & 1.820 .449 .803 & 148 & 1 & 6 & 5 & 3 & 15 & Stepdown method \\
\hline 14 & c & 55374 & 546770 & 2.582 .136 .383 & 725.974 .575 & $\quad 3.308 .110 .958$ & 120 & 1 & 11 & 15 & 5 & 32 & Stepdown method \\
\hline 15 & D & 34454 & 151967 & 777.340 .559 & 250.465 .965 & 1.027 .806 .524 & 70 & 1 & 4 & 4 & 3 & 12 & Stepdown method \\
\hline 16 & D & 52145 & 145257 & 1.849 .812 .191 & 519.074 .864 & $\quad 2.368 .887 .055$ & 53 & 1 & 3 & 3 & 1 & 8 & Direct method only \\
\hline 17 & D & 100258 & 721965 & 5.239.508.199 & 1.419 .808 .520 & 6.659 .316 .720 & 123 & 2 & 8 & 11 & 2 & 23 & $\begin{array}{l}\text { Direct method mixed with } \\
\text { stepdown method }\end{array}$ \\
\hline 18 & D & 49959 & 311920 & 1.969 .438 .664 & 574.918 .325 & 2544.356 .989 & 147 & 1 & 6 & 7 & 1 & 15 & Stepdown method \\
\hline 19 & D & 38374 & 146224 & 895.180 .535 & 263.187 .295 & 1.158 .367 .830 & 88 & 1 & 6 & 8 & 2 & 17 & $\begin{array}{l}\text { Direct method mixed with } \\
\text { stepdown method }\end{array}$ \\
\hline 20 & $\mathrm{E}$ & 114186 & 650301 & 5.944.017.002 & 1.937 .397 .089 & 7.881 .414 .091 & 291 & 1 & 17 & 22 & 25 & 65 & Stepdown method \\
\hline
\end{tabular}

\section{Figures}




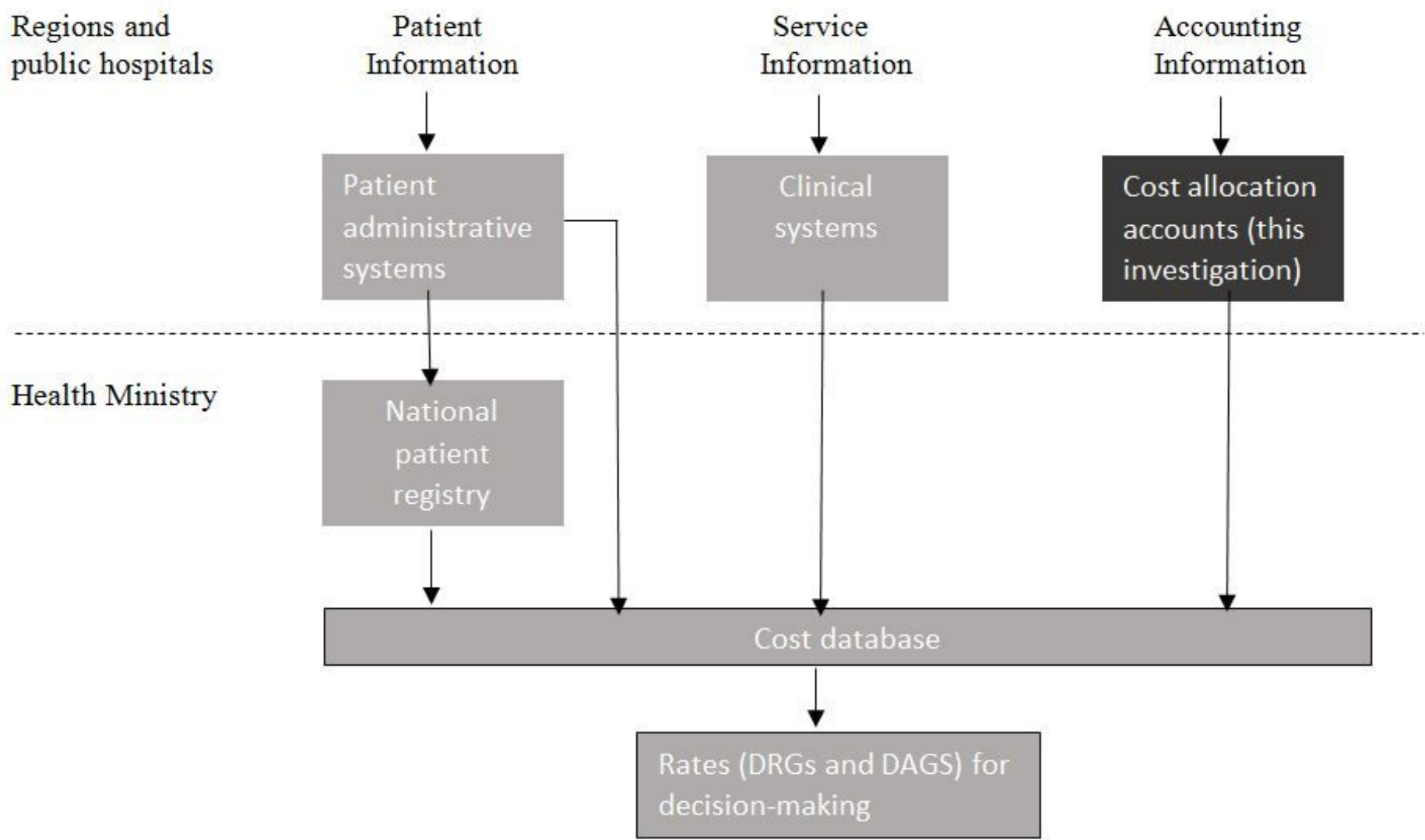

Source: The National Audit Office of Denmark (14)

\section{Figure 1}

Dataflow for DRG and DAGS calculations 